\title{
Biophysics, Other
}

National Cancer Institute

\section{Source}

National Cancer Institute. Biophysics, Other. NCI Thesaurus. Code C18655.

A value used as a form filler when no specified type of Biophysics is appropriate. 